\title{
Benign Appendix Neoplasm
}

National Cancer Institute

\section{Source}

National Cancer Institute. Benign Appendix Neoplasm. NCI Thesaurus. Code C4773.

A non-metastasizing neoplasm arising from the appendix. 